\title{
Differentiation of murine male germ cells to spermatozoa in a soft agar culture system
}

\begin{abstract}
Mahmoud Abu Elhija ${ }^{1}$, Eitan Lunenfeld ${ }^{2}$, Stefan Schlatt ${ }^{3}$ and Mahmoud Huleihel ${ }^{1}$
Establishment of an in vitro system that allows the development of testicular germ cells to sperm will be valuable for studies of spermatogenesis and future treatments for male infertility. In the present study, we developed in vitro culture conditions using three-dimensional agar culture system (SACS), which has the capacity to induce testicular germ cells to reach the final stages of spermatogenesis, including spermatozoa generation. Seminiferous tubules from testes of 7-day-old mice were enzymatically dissociated, and intratubular cells were cultured in the upper layer of the SACS in RPMI medium supplemented with fetal calf serum (FCS). The lower layer of the SACS contained only RPMI medium supplemented with FCS. Colonies in the upper layer were isolated after 14 and $\mathbf{2 8}$ days of culture and were classified according to their size. Immunofluorescence and real-time PCR were used to analyse specific markers expressed in undifferentiated and differentiated spermatogonia (Vasa, Dazl, OCT-4, C-Kit, GFR$\alpha-1, C D 9$ and $\alpha-6$-integrin), meiotic cells ( $L D H, C r e m-1$ and Boule) and post-meiotic cells (Protamine-1, Acrosin and SP-10). Our results reveal that it is possible to induce mouse testicular pre-meiotic germ cell expansion and induce their differentiation to spermatozoa in SACS. The spermatozoa showed normal morphology and contained acrosomes. Thus, our results demonstrate that SACS could be used as a novel in vitro system for the maturation of pre-meiotic mouse germ cells to post-meiotic stages and morphologically-normal spermatozoa.
\end{abstract}

Asian Journal of Andrology (2012) 14, 285-293; doi:10.1038/aja.2011.112; published online 7 November 2011

Keywords: acrosome; agar; in vitro culture; meiosis; spermatogenesis; spermatogonia; spermatozoa; testis

\section{INTRODUCTION}

In mammalian species, spermatogenesis occurs in the seminiferous tubules of the testis and relies on the appropriate expansion of undifferentiated and differentiated spermatogonia prior to the entry of germ cells into meiosis and subsequent spermiogenesis. ${ }^{1,2}$

Several attempts have previously been made to establish and optimize germ cell cultures using specific culture media, growth factors, sera, conditioned media of testicular or non-testicular origin and feeder layers. ${ }^{1,3-12}$ However, none of these conditions have successfully generated spermatozoa.

Most attempts to culture male germ cells have been performed using two-dimensional cell culture systems. We recently described a novel three-dimensional cell culture system using soft agar (SACS $)^{11}$ (Figure 1). This culture system is more representative of the in vivo conditions as it mimics some aspects of the natural three-dimensional environment a cell is exposed to in an organ. ${ }^{13,14}$ In the past, the threedimensional SACS has been used to investigate proliferation and differentiation of bone marrow and haematopoietic cells in vitro. ${ }^{15,16} \mathrm{We}$ hypothesize that this approach is adaptable to male germ cells and will optimize the microenvironment for clonal expansion and differentiation of germ cells. In a recent review, we provided preliminary evidence that pre-meiotic mouse germ cells differentiated into morphologically normal sperm using SACS. ${ }^{17}$ Here, we provide all experimental details, and we present additional evidence by detailed analysis of germ cell clusters, using real-time PCR and immunofluorescence. We provide evidence that a progressive development of germ cells occurs in vitro and that SACS is an appropriate strategy for the expansion and differentiation of immature mouse testicular germ cells. Starting with pre-meiotic germ cells, SACS supports the development of mature spermatozoa with intact acrosomes.

\section{MATERIALS AND METHODS}

\section{Animals}

This investigation was conducted in accordance with the Guiding Principles for the Care and Use of Research Animals Promulgated by the Society for the Study of Reproduction. Sexually mature (4- to 8-week-old) or immature (7- and 14-day-old) BALB/c mice (Harlan Laboratories, Jerusalem, Israel) were used.

\section{Chemicals and reagents}

Collagenase V and DNAase (2000 KU) were obtained from Sigma (St Louis, MO, USA). RPMI, penicillin, streptomycin and fetal calf serum (FCS) were purchased from Beit Haemek Biological Industries (Beit Haemek, Israel). Agar was purchased from Bacto-Agar (Difco Laboratories, Detroit, MI, USA). 


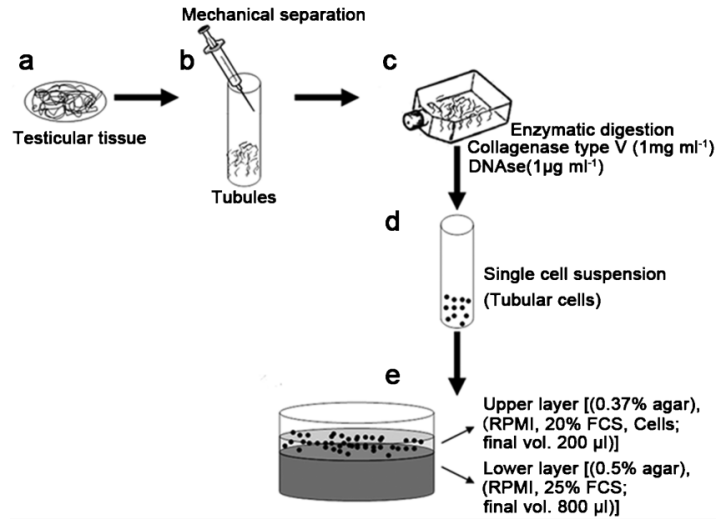

Figure 1 Scheme of the SACS. The SACS was composed of two layers: the solid lower layer $(0.5 \%(\mathrm{w} / \mathrm{v})$ agar) and the soft upper layer $(0.37 \%(\mathrm{w} / \mathrm{v})$ agar $)$, which were cultured in 24-well plates. Testicular tissue from immature mice (a) was mechanically separated to obtain interstitial tissue and tubules (b). The tubules were enzymatically digested (c), and the isolated tubular cells (d) were used for culture in the upper phase of the SACS (e). Tubular cells $\left(10^{6}\right.$ cells per well per $200 \mu$ l) were cultured in the upper layer of the soft agar medium. Cultures were incubated in $5 \% \mathrm{CO}_{2}$ incubator at $37^{\circ} \mathrm{C}$. FCS, fetal calf serum; SACS, Soft Agar Culture System.

\section{Isolation of mouse spermatogonial cells}

Tubular cells were isolated from the testes of 7-day-old male BALB/c mice. At this age, the testis does not contain any meiotic germ cells and the seminiferous epithelium comprises proliferating Sertoli cells and a mixture of undifferentiated and differentiating type A spermatogonia. Testicular cell suspensions were obtained as described by Zeyse et al. ${ }^{18}$ Briefly, the testes were decapsulated and mechanically digested by multiple aspirations through pipette tips (eight aspirations through 2-mm diameter tips followed by 10 aspirations through $1-\mathrm{mm}$ diameter tips) into a $50-\mathrm{ml}$ syringe following the addition of $20 \mathrm{ml}$ phosphate-buffered saline (PBS). Mechanical digestion was continued until the tubules were completely dissociated. Thereafter, the tubules were allowed to settle by gravity and washed three times with PBS. Supernatants containing the interstitial cells were discarded. The tubules were transferred to a $50-\mathrm{ml}$ culture flask and subjected to digestion in saline containing collagenase type $\mathrm{V}\left(1 \mathrm{mg} \mathrm{ml}{ }^{-1}\right)$ and DNAse $\left(1 \mu \mathrm{g} \mathrm{ml}^{-1}\right)$ for $25 \mathrm{~min}$ in a shaking water bath $(120$ cycles $\min ^{-1}$ at $37^{\circ} \mathrm{C}$ ). The suspension was then aspirated three times with a pipette and incubated for an additional $5 \mathrm{~min}$ in a $37^{\circ} \mathrm{C}$ shaking water bath. This isolation procedure resulted in a single cell suspension consisting of Sertoli cells and spermatogonia (as these are the only germ cells present at postnatal day 7) as well as a small proportion of peritubular cells.

The intratubular cell suspension was filtered through sterile surgical gauze and washed by centrifugation for $5 \mathrm{~min}$ at $200 \mathrm{~g}$ at room temperature. The cells were suspended in RPMI and counted.

The same method, using testes from 14-day-old and mature mice, was used to prepare a suspension of tubular cells to be used as a positive control for immunostaining and real-time PCR analysis. The suspension from adult mice contains germ cells of all spermatogenic stages (undifferentiated spermatogonia to spermatozoa).

\section{SACS}

The conditions for the clonogenic culture of testicular cells in SACS were selected in accordance with previous experiments performed on haematopoietic stem cells. ${ }^{16}$ Briefly, the SACS was composed of two layers (Figure 1): the solid lower layer $(0.5 \%(\mathrm{w} / \mathrm{v})$ agar) and the soft upper layer $(0.37 \%(\mathrm{w} / \mathrm{v})$ agar $)$ and cultured in 24 -well plates. To establish definite concentrations of agar and cells, $0.7 \%(\mathrm{w} / \mathrm{v})$ agar and $1 \%(\mathrm{w} / \mathrm{v})$ agar were mixed with distilled water during the preparation of the upper and lower phases, respectively. Tubular cells $\left(10^{6}\right.$ cells per well per $200 \mu \mathrm{l}$ ) were cultured in the upper layer of the soft agar medium (0.37\% agar+RPMI+20\% (v/v) FCS, tubular cells; final volume of $200 \mu \mathrm{l}$ ). Cell suspensions were added to the RPMI prior to mixing with the agar. The agar and the RPMI/cells were mixed at $37^{\circ} \mathrm{C}$ to avoid heat-induced cellular stress and premature agar coagulation. This layer was added on top of the lower layer after it had solidified. The solid agar base (lower layer; final volume of $800 \mu \mathrm{l}$ ) contained both RPMI and 25\% (v/v) FCS and 0.5\% (w/v) agar only. All culture experiments were maintained in standard cell culture incubators at $37^{\circ} \mathrm{C}$ and $5 \% \mathrm{CO}_{2}$ for up to 4 weeks.

Cells in the culture dish were defined as colonies when more than 50 cells were present and were further classified into colonies containing more than 50 cells but less than 150 cells (small; S), more than 150 but less than 300 cells (medium; M) and more than 300 cells (large; L). The analysis of colonies was performed microscopically after incubation for two or four weeks. Colonies (, M and L) were counted separately in each well of the same treatment group (4-6 wells in each treatment group).

Colonies (S, M and L) were manually picked under microscopic observation using a microtip, and the cells in this sample were processed for RNA detection and immunofluorescence analysis. Colonies from all wells of the same treatment were determined with respect to their size and were collected into the same tube for RNA extraction. Cells from different experiments were stored in different tubes and analysed separately. In addition, extracted RNA from the colonies was examined for the expression of androgen binding protein $(A B P)$ (a specific marker for Sertoli cells), alpha-smooth muscle $(\alpha-S m)$ (a specific marker for peritubular cells; P) and immune cell markers, such as those for macrophages (CD11-b).

\section{Analysis to evaluate spermatogonial cell differentiation stages}

Extraction of total RNA for reverse transcription (RT-) PCR and real time PCR analysis. First-strand complementary DNAs (cDNAs) were synthesized from $2.5 \mu \mathrm{g}$ total RNA (from testicular homogenates) or using the entire extracted RNA when colonies were picked) with $0.5 \mu \mathrm{g}$ random oligonucleotide primers (Roche Molecular Biochemicals, Mannheim, Germany) and $200 \mathrm{U}$ of Moloney-Murine Leukaemia Virus-Reverse Transcriptase (M-MLV-RT; Life Technologies, Inc., Paisley, Scotland, UK) in a total volume of $20 \mu \mathrm{l}$ Tris- $\mathrm{HCl}-\mathrm{MgCl}$ reaction buffer, supplemented with DTT, dNTPs $\left(0.5 \mathrm{mmol} \mathrm{l}^{-1}\right.$; Roche Molecular Biochemicals) and RNase inhibitor (40 U; Roche Molecular Biochemicals). The RT reaction was performed for $1 \mathrm{~h}$ at $37{ }^{\circ} \mathrm{C}$ and stopped for $10 \mathrm{~min}$ at $75{ }^{\circ} \mathrm{C}$. The volume of $20 \mu \mathrm{l}$ was subsequently filled up to $60 \mu \mathrm{l}$ with treatment water. Negative controls for the RT reaction were prepared in parallel, using the same reaction preparations with the same samples, without M-MLV. RT-PCR was performed using cDNA samples at a final dilution of $1: 15$ with two pairs of oligonucleotide primers (Sigma) (Table 1).

To assess the absence of genomic DNA contamination in RNA preparations and RT-PCR reactions, PCR was performed with negative controls of the RT reaction (RT-) and without cDNA (cDNA-). The PCR reactions were carried out on a Cycler II System Thermal Cycler (Ericomp, San Diego, CA, USA). Twenty microlitres of each PCR product was run on a $2 \%$ agarose gel that contained ethidium bromide and was photographed under UV light. The amount of mRNA used in each RT-PCR experiment was $50 \mathrm{ng}$. 
Table 1 Reverse transcription (RT-) PCR primers

\begin{tabular}{|c|c|c|c|c|c|}
\hline Stage & Target & Primer & Sequence & $T_{m}\left({ }^{\circ} \mathrm{C}\right)$ & Size $(b p)$ \\
\hline \multirow[t]{14}{*}{ Pre-meiotic } & \multirow[t]{2}{*}{ Nanog } & Forward & 3'-AGGGTCTGCTACTGAGATGCTCTG-5' & \multirow[t]{2}{*}{57} & \multirow[t]{2}{*}{363} \\
\hline & & Reverse & 5'-CAACCACTGGTTTTTCTGCCACCG-3' & & \\
\hline & \multirow[t]{2}{*}{ VASA } & Forward & 3'-GGTCCAAAAGTGACATATATACCC-5' & \multirow[t]{2}{*}{57} & \multirow[t]{2}{*}{419} \\
\hline & & Reverse & 5'-TTGGTTGATCAGTTCTCGAGT-3' & & \\
\hline & \multirow[t]{2}{*}{ OCT-4 } & Forward & 3'-AGAAGGAGCTAGAACAGTTTGC-5' & \multirow[t]{2}{*}{57} & \multirow[t]{2}{*}{416} \\
\hline & & Reverse & 5'-CGGTTACAGAACCATACTCG-3' & & \\
\hline & \multirow[t]{2}{*}{$C-K I T$} & Forward & 3'-GCATCACCATCAAAAACGTG-5' & \multirow[t]{2}{*}{57} & \multirow[t]{2}{*}{331} \\
\hline & & Reverse & 5'-GATAGTCAGCGTCTCCTGGC-3' & & \\
\hline & \multirow[t]{2}{*}{$G F R-\alpha-1$} & Forward & 3'-GGCCTACTCGGGACTGATTGG-5' & \multirow[t]{2}{*}{57} & \multirow[t]{2}{*}{462} \\
\hline & & Reverse & 5'-GGGAGGAGCAGCCATTGATTT-3' & & \\
\hline & \multirow[t]{2}{*}{$\alpha$-6-integrin } & Forward & 3'-AGGAGTCGCGGGATATCTTT-5' & \multirow[t]{2}{*}{57} & \multirow[t]{2}{*}{502} \\
\hline & & Reverse & 5'-CAGGCCTTCTCCGTCAAATA-3' & & \\
\hline & \multirow[t]{2}{*}{ CD9 } & Forward & 3'-ATCTTCTGGCTCGCTGGCATT-5' & \multirow[t]{2}{*}{57} & \multirow[t]{2}{*}{373} \\
\hline & & Reverse & 5'-ATGGCTTTGAGTGTTTCCCGCT-3' & & \\
\hline \multirow[t]{4}{*}{ Meiotic } & \multirow[t]{2}{*}{ Crem-1 } & Forward & 5'-TTCTTTCACGAAGACCCTCA-3' & \multirow[t]{2}{*}{57} & \multirow[t]{2}{*}{114} \\
\hline & & Reverse & 5'-TGTTAGGTGGTGTCCCTTCT-3' & & \\
\hline & \multirow[t]{2}{*}{$L D H$} & Forward & 3'-GCACGGCAGTCTTTTCCTTAGC-5' & \multirow[t]{2}{*}{57} & \multirow[t]{2}{*}{585} \\
\hline & & Reverse & 5'-TCGCGCCAGATCAGTCACAG-3' & & \\
\hline \multirow[t]{2}{*}{ Post-meiotic } & \multirow[t]{2}{*}{ Protamine } & Forward & 3'-GGCCACCACCACCACAGACACAGGCG-5' & 57 & 188 \\
\hline & & Reverse & 5'-TTAGTGATGGTGCCTCCTACATTTCC-3' & & \\
\hline Sertoli cells & $A B P$ & Forward & 3'-GGAGAAGAGAGACTCTGTGG-5' & 57 & 900 \\
\hline & & Reverse & 5'-GCTCAAGACCACTTTGACTC-3' & & \\
\hline Peritubular cells & $\alpha-S m$ & Forward & 3'-CATCAGGCAGTTCGTAGCTC-5' & 57 & 524 \\
\hline & & Reverse & 5'-CGATAGAACACGGCATCATC-3' & & \\
\hline Leydig cells & $L H R$ & Forward & 3'-AATACACAACTGTGCATTCAAC-5' & 57 & 451 \\
\hline & & Reverse & 5'-ATTTGGATGAAGTTCAGAGGTT-3' & & \\
\hline Macrophages & $C D 11-b$ & Forward & 3'-GTCAGTGGCATGGTG-5' & 57 & 524 \\
\hline & & Reverse & 5'-CAAAGCTTCTGCTGT-3' & & \\
\hline House keeping gene control & $\beta$-actin & Forward & 3'-AGAGGGAAATCGTGCGTGAC-5' & 57 & 485 \\
\hline & & Reverse & 5'-GCCGGACTCATCGTACTCCT-3' & & \\
\hline
\end{tabular}

\section{Real-time PCR analysis}

Real-time quantitative PCR amplification of total cDNA (500 ng per sample) used specific primers of the different sequences (Table 2).

The reactions were conducted following the protocol for the Absolute qPCR SYBR Green mix (ABgene House, Blenheim Road, Epsom, UK) containing modified Tbr DNA polymerase, SYBR Green, optimized PCR buffer, $5 \mathrm{mmol}{ }^{-1} \mathrm{MgCl}_{2}$, dNTP mix and dUTP. The PCR reaction was performed using a real-time PCR machine (MyIQ; Bio-Rad Laboratories, Richmond, CA, USA) according to the manufacturer's instructions. The following PCR protocol repeated 45-50 times was used: denaturation $\left(95{ }^{\circ} \mathrm{C}\right.$ for $10 \mathrm{~min}$ ), amplification and quantification $\left(94^{\circ} \mathrm{C}\right.$ for $\left.10 \mathrm{~s}\right), 72^{\circ} \mathrm{C}$ for $30 \mathrm{~s}$ with a single fluorescence measurement, melting curve $\left(60-95{ }^{\circ} \mathrm{C}\right.$ with a heating rate of $0.5^{\circ} \mathrm{C}$ per $30 \mathrm{~s}$ and a continuous fluorescence measurement) and a cooling step to $4{ }^{\circ} \mathrm{C}$. PCR products were identified and distinguished by the generated melting curve. The 'threshold cycle' $\left(C_{\mathrm{t}}\right)$ values, which represented the cycle number at which the sample fluorescence rose statistically above background, and crossing points for each transcript were defined. The relative quantity of gene expression was analysed by the $2^{-\Delta \Delta \mathrm{C}_{\mathrm{t}}}$ method.

To ensure accurate products and the absence of contaminating DNA, all real-time PCR products were also examined in parallel by PCR analysis with the negative controls.

\section{Immunofluorescence staining of cells from colonies developed in} SACS

Cells were fixed in cold methanol for $10 \mathrm{~min}$ and stored at $4{ }^{\circ} \mathrm{C}$ until stained. Before the primary antibodies were applied, nonspecific background staining was blocked with PBS containing 4\% FCS and/ or antibodies against the relevant IgG isotype. Thereafter, polyclonal rabbit anti-mouse C-Kit $\left(4 \mu \mathrm{g} \mathrm{ml}^{-1}\right)$, rabbit anti-mouse GFR- $\alpha-1$ $\left(4 \mu \mathrm{g} \mathrm{ml}^{-1}\right)$, rabbit anti-mouse CD9 $\left(4 \mu \mathrm{g} \mathrm{ml}^{-1}\right)$, rabbit anti-mouse $\alpha$-6-integrin $\left(4 \mu \mathrm{g} \mathrm{ml}^{-1}\right)$, rabbit anti-ETQEDAQKILQEAEKLNYKDKKLN peptide $(1: 300)$, rabbit anti-mouse Crem-1 $\left(4 \mu \mathrm{g} \mathrm{ml}^{-1}\right)$, goat anti-mouse lactate dehydrogenase $(\mathrm{LDH})\left(4 \mu \mathrm{g} \mathrm{ml} \mathrm{m}^{-1}\right)$, goat antimouse Protamine $\left(4 \mu \mathrm{g} \mathrm{ml}{ }^{-1}\right)$, goat anti-mouse Acrosin $(4 \mu \mathrm{g}$ $\left.\mathrm{ml}^{-1}\right)$, goat anti-mouse Dazl $\left(4 \mu \mathrm{g} \mathrm{ml}^{-1}\right)$ and rabbit anti-mouse Vasa $\left(4 \mu \mathrm{g} \mathrm{ml}^{-1}\right)$ antibodies were used as primary antibodies. All antibodies were purchased from Santa Cruz Biotechnology, Inc. (Santa Cruz, CA, USA). The primary antibodies were incubated over night at $4{ }^{\circ} \mathrm{C}$ in PBS containing 4\% FCS. PBS was used for all subsequent washing steps. Fluorescein-conjugated antibodies (Cy3; donkey anti-rabbit or donkey anti-goat antibodies; $4 \mu \mathrm{g} \mathrm{ml}^{-1}$; Jackson ImmunoResearch, West Grove, PA, USA) were used for visualisation of the signal according to the suppliers' directions. After $1 \mathrm{~h}$ of incubation, the slides were washed in PBS and subsequently subjected to DAPI staining (Santa Cruz Biotechnology, Inc). Negative controls were included for each specimen using PBS containing FCS/BSA instead of the primary antibodies.

Immunofluorescence staining of mouse testicular tissue

Four-micron thick sections from formalin-fixed, paraffin-embedded testicular tissue blocks were mounted on saline-coated slides, dried at $37{ }^{\circ} \mathrm{C}$ for $48 \mathrm{~h}$ and stored at room temperature. Before the primary antibodies were applied, nonspecific background staining was blocked with PBS containing $0.05 \%$ casein and/or relevant antibodies for the 
Table 2 Real-time PCR primers

\begin{tabular}{|c|c|c|c|c|c|}
\hline Stage & Target & Primer & Sequence & $T_{m}\left({ }^{\circ} \mathrm{C}\right)$ & Size $(b p)$ \\
\hline \multirow[t]{11}{*}{ Pre-meiotic } & \multirow[t]{2}{*}{ Vasa } & Forward & 5'-GTATTCATGGTGATCGGGAGCAG-3' & \multirow[t]{2}{*}{60} & \multirow[t]{2}{*}{88} \\
\hline & & Reverse & 5'-CAACAAGAACTGGGCACTTTCCA-3' & & \\
\hline & Dazl & Forward & 5'-GCACTCAGTCTTCATCAGCAACCA-3' & 60 & 187 \\
\hline & \multirow[t]{2}{*}{ OCT-4 } & Forward & 5'-GAAGTTGGAGAAGGTGGACCA-3' & \multirow[t]{2}{*}{60} & \multirow[t]{2}{*}{91} \\
\hline & & Reverse & 5'-GCTTCAGCAGCTTGGCAAA-3' & & \\
\hline & C-Kit & Forward & 5'-TGATTGTGCTGGATGATGGATGG-3' & 60 & 106 \\
\hline & $G F R-\alpha-1$ & Reverse & 5'-TGGTACAGGGGGTGATGTAGG-3' & 60 & 127 \\
\hline & \multirow[t]{2}{*}{ CD9 } & Forward & 5'-ATGGCTTTGAGTGTTTCCCGCT-3' & \multirow[t]{2}{*}{60} & \multirow[t]{2}{*}{372} \\
\hline & & Reverse & 5'- ATCTTCTGGCTCGCTGGCATT -3' & & \\
\hline & \multirow[t]{2}{*}{$\alpha-6$-integrin } & Forward & 5'-CCGGCCAGTGATTAACATTCT-3' & \multirow[t]{2}{*}{60} & \multirow[t]{2}{*}{62} \\
\hline & & Reverse & 5'-TGAGCCACACATGGACTTCT-3' & & \\
\hline Meiotic & Crem-1 & Forward & 5'-TTCTTTCACGAAGACCCTCA-3' & 60 & 114 \\
\hline \multirow{5}{*}{ Post- meiotic } & Protamine & Reverse & 5'-GTGATGGTGCCTCCACATTTCCT-3' & 60 & 169 \\
\hline & $S P-10$ & Forward & 5'-ATCTGAAGGGTTTGGAGTGAGAG-3' & 60 & 134 \\
\hline & & Reverse & 5'-TGGGTCTTTATCTGGTTGGATCTGCC-3' & & \\
\hline & Acrosin & Forward & 5'-TGTCCGTGGTTGCCAGGATAACA-3' & 60 & 85 \\
\hline & & Reverse & 5'-AATCCGGGTACCTGTTGTGAGTT-3' & & \\
\hline House keeping gene control & $\beta$-actin & Forward & 5'-AGAGGGAAATGTGCGTGAC-3' & 60 & 99 \\
\hline & & Reverse & 5'-CAATAGTGATGACCTGGCCGT-3' & & \\
\hline
\end{tabular}

relevant of IgG isotype. This solution was also used for incubation with primary antibodies. For antigen retrieval, sections were boiled in $6 \mathrm{~mol} \mathrm{l}^{-1}$ urea for $10 \mathrm{~min} .{ }^{19}$ Thereafter, tissues were stained with the different primary and secondary antibodies using methods similar to those described for staining cells above. Negative controls were included for each specimen using PBS/casein/relevant IgG isotype instead of the primary antibodies.

\section{Identification of spermatozoa in SACS}

The entire agar well ( $1 \mathrm{ml}$, with all colonies and cells) was transferred to a cassette for fixation in formalin ( $250 \mathrm{ml}$ of $4 \%$ formalin) for $24 \mathrm{~h}$. After fixation, the agar was washed in different concentrations of alcohol $(30 \%, 50 \%, 70 \%, 85 \%, 95 \%$ and $100 \%)$, for $30 \mathrm{~min}$ in each concentration.

At the end of the washing process, the agar containing colonies (around $0.2 \mathrm{ml}$ of loosely agar) was transferred from the cassette into an Eppendorf tube. One millilitre of saline was added to the tube and was repeatedly pipetted to destroy the agar. The suspension was transferred to a slide and left overnight in a laminar flow hood to evaporate the water while most of the residual agar reverted to powder. Thereafter, the slide was fixed in cold methanol for $15 \mathrm{~min}$ and dried at room temperature before staining with haematoxylin and eosin to identify cells.

\section{Differentiation of male germ cells to spermatozoa in SACS}

Differentiation of tubular cells to spermatozoa was determined in SACS after 30 days of culture (in 11 different experiments using 32 samples).

\section{Acrosome identification in sperm cells}

The presence of acrosomes was confirmed in the spermatozoa that developed after 30 days of culture in SACS (in four different experiments using four samples).
The presence of acrosomes in spermatozoa was determined using a fluorescence microscope. Sperm cells isolated from SACS were smeared on microscope slides at room temperature for $10 \mathrm{~min}$. After air drying, sperm smears were fixed in cold absolute methanol for $15 \mathrm{~min}$, washed once in Tris-buffered saline (TBS) and twice in distilled water at $5 \mathrm{~min}$ intervals, air dried, incubated with lectin from Archis hypogaea (peanut)-conjugated FITC (PNA-FITC) $(\text { Sigma })^{20}\left(25 \mu \mathrm{g} \mathrm{ml}^{-1}\right)$ in Trisbuffered saline for $30 \mathrm{~min}$, washed with distilled water and mounted with FluoroGuard Antifade (BioRad Laboratories).

Spermatozoa with green staining over the acrosomal cap were considered to be cells with intact acrosome.

\section{Microscopy}

Samples were observed with an Olympus IX70 microscope (Olympus, Novato, CA, USA). Digital images and signal intensity charts were prepared using Image-Pro Plus (Media Cybernetics, Bethesda, MD, USA), Microsoft Excel and Adobe Photoshop 7.0 software.

\section{Data analysis and statistical evaluation}

Each culture condition was tested in 4-6 wells. The plotted data are means calculated from 3-10 repeats of the experiment. The standard deviation represents the variability between independent experiments. For quantitative data on RNA expression and colony counts, the single data points obtained in independent experiments from each well with identical culture conditions were combined to calculate mean \pm s.d. One-way ANOVA and Bonferroni's multiple comparison test were used to estimate statistical significance, and $P$ values $<0.05$ were considered significant.

\section{RESULTS}

Isolated tubular cells from 7-day-old and mature (8-week-old) mice were examined by RT-PCR (Figure 2a) and immunofluorescence analysis (for tubular cells from 7-day-old mice; Figure $2 \mathbf{b}$ ) to 
a

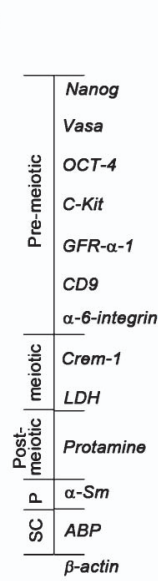

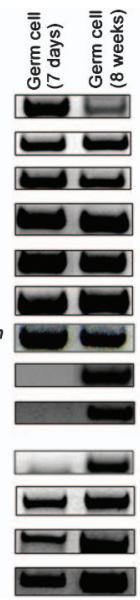
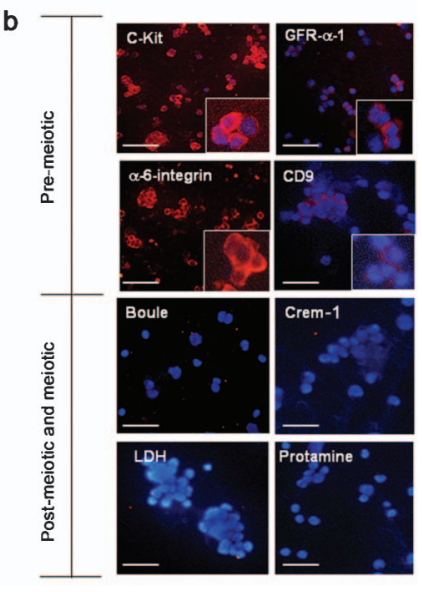

Figure 2 Characterisation of isolated tubular cells before culture in SACS. Isolated tubular cells were examined by RT-PCR analysis using specific markers for pre-meiotic (Nanog, Vasa, OCT-4, C-Kit, GFR- $\alpha-1$, CD9 and $\alpha-6$ integrin), meiotic (Crem-1 and LDH) and post-meiotic stages (Protamine) and also for Sertoli cells $(A B P)$ and peritubular cells $(P)(\alpha-S m)(a)$ Immunofluorescence analysis for testicular tubular cells from 7-day-old mice was used to identify cells positive for pre-meiotic (C-Kit, GFR- $\alpha-1, \alpha-6$-integrin and $C D 9$ ), meiotic (Boule, Crem-1 and $L D H$ ) and post-meiotic markers (Protamine) (b). Scale bars $=10 \mu \mathrm{m}$. LDH, lactate dehydrogenase; SACS, Soft Agar Culture System; SC, Sertoli cell.

characterize the isolated cells and their differentiation stages before culturing in SACS. Our results showed expression of the pre-meiotic genes Nanog, Vasa, OCT-4, C-Kit, GFR- $\alpha-1, C D 9$ and $\alpha-6$-integrin in tubular cells from 7-day-old mice. Meiotic and post-meiotic gene expression (Crem-1, LDH and Protamine) could not be observed. In addition, Sertoli, peritubular, macrophages and Leydig cells were also

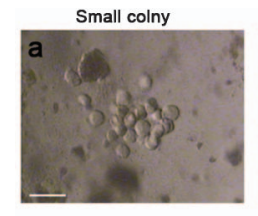

$$
\text { d }
$$
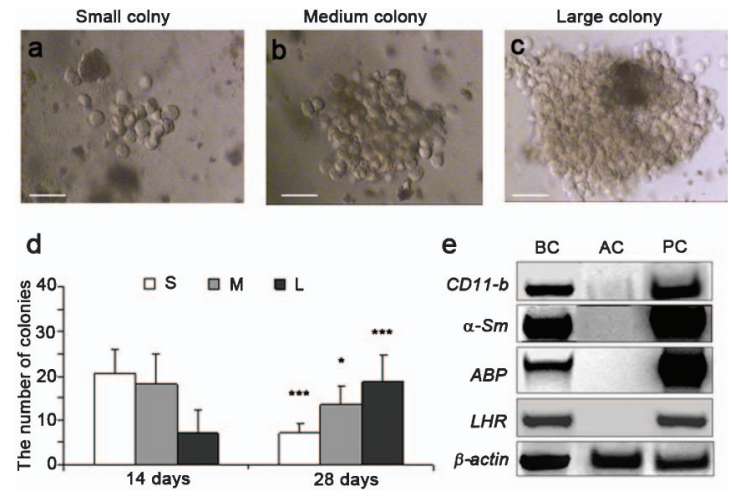

Figure 3 Tubular cell colonies development in the SACS. Tubular cells ( $10^{6}$ cells per well) were cultured in the upper layer of the SACS. The lower layer of the SACS consisted of RPMI containing $20 \%$ FCS. The size of the colonies in the upper layer was evaluated after 14 and 28 days of culture. (a) Colonies were designated as small (S) when they contained around 50 cells; (b) medium (M) when they contained around 150 cells; and (c) large (L) when they contained more than 300 cells. (d) The capacity of tubular cells to form S, M or L colonies in SACS was examined after 14 and 28 days of culture. $* P<0.05$, $* * * P<0.001$, compared with 14 days. (e) The expression of markers for Sertoli, peritubular, macrophage and Leydig cells ( $A B P, \alpha-S m, C D 11-b$ and $L H R$ respectively) was examined by PCR analysis using specific primers for each marker. Scale bars $=10 \mu \mathrm{m}$. BC, before culture; AC, after culture (colonies); PC, positive control (RNA from the testis of an 8-week-old mouse). FCS, fetal calf serum; SACS, Soft Agar Culture System. present when examined by specific markers $(A B P$ and $\alpha$-Sm; Figure 2a and $3 \mathbf{e}$ ) and $C D 11-b$ and $L H R$ ( $L H$ receptor) (Figure $3 \mathbf{e}$ ) before culture, respectively). Thus, the isolated cells contained only pre-meiotic germ cells in addition to somatic cells.

Isolated tubular cells were cultured in the upper layer of SACS (Figure 1). Distinct colonies in the upper layer were classified according to their size, as presented in Figure $\mathbf{3 a - c}$. Colonies of different sizes were encountered after 14 and 28 days of culture in SACS (Figure 3d). The number of small and medium colonies was greater than the number of large colonies after 14 days in SACS. A significant decline in the number of small $(P<0.001)$ and medium $(P<0.05)$ colonies was detected after 28 days of culture compared to 14 days in SACS. In contrast, the number of large colonies increased after 28 days compared to 14 days in SACS $(P<0.001)$ (Figure 3d).

The handpicked colonies did not contain RNA indicating the presence of Sertoli, peritubular, macrophages or Leydig cells as examined by PCR analysis using specific markers for those cells $(A B P, \alpha-S m$, $C D 11-b$ or LHR, respectively) (Figure 3e).

We examined testicular cells freshly isolated from 7-, 14-, 28- and 40-day-old mice for pre-meiotic (OCT-4, GFR- $\alpha-1, C$-Kit, CD 9 and $\alpha$ 6-integrin), meiotic ( $\mathrm{LDH}$ and Crem-1) and post-meiotic (Protamine, Acrosin and SP-10) markers (Table 3). The results show that meiotic and post-meiotic genes were expressed in 28- and 40-day-old mice but not at the earlier time points. Determination of cell type-specific marker expression in colonies was performed by real-time PCR analysis (Table 4) of 14- and 30-day cultures (six independent experiments for each) when each sample run in one to five wells Each data point represents the results from colonies collected from a single well. In general, analyses conducted prior to culturing the cells in SACS indicated that only pre-meiotic markers (OCT-4, GFR- $\alpha-1, C-K i t, C D 9$ and $\alpha$-6-integrin) were present. After 14 and 30 days of culture in SACS, the expression of the pre-meiotic markers became variable. This variability existed between different experiments and also between individual colonies within the same experiment. After 2 weeks of culture, meiotic and post-meiotic markers were occasionally detectable irrespective of the presence or depletion of pre-meiotic markers (Table 4). After 30 days of culture, meiotic and post-meiotic markers were consistently expressed (Table 4). With the exception of CD9 and OCT-4, the average expression of pre-meiotic markers in tubular cells cultured in SACS for 14 days and 30 days (respectively) was significantly reduced (Table 4 ). These results correspond to the in vivo situation, with the exception that the expression levels of $C D 9$ decreased with age (Table 3 ). Meiotic and post-meiotic markers significantly increased with time in culture in SACS (except for $L D H$, Acrosin and SP-10 after 14 days) (Table 4). This increase in meiotic and post-meiotic markers in SACS cultures corresponded to the situation in vivo (Table 3 ).

In general, the composition of markers did not depend on the size of the colony. We confirmed the RT-PCR data on germ cell maturation by immunohistochemical detection of proteins specific for premeiotic, meiotic and post-meiotic germ cells in colonies isolated after 28 days of culture in SACS (Figure $\mathbf{4 a}$ and $\mathbf{4 b}$ ). The protamine signal was localized differently in the cultured cells compared to cells in the sections. This difference could be related to the in vitro culture conditions of the cells in the agar system. We confirmed the validity of these markers in testicular tissue from 7-day-old and 8-week-old mice (Figure 4c and 4d), and for 'boule' staining in our previous study ${ }^{11}$ ).

We also confirmed the presence of post-meiotic germ cells by a series of micrographs depicting progressive stages of differentiating spermatids up to morphologically normal spermatozoa (Figure 5a 
Table 3 Expression of spermatogenesis genes in cells from mouse tubular cells of different ages

\begin{tabular}{|c|c|c|c|c|c|c|c|c|c|c|c|}
\hline \multirow{2}{*}{ Age } & \multicolumn{6}{|c|}{ Pre-meiotic } & \multicolumn{2}{|c|}{ Meiotic } & \multicolumn{3}{|c|}{ Post-meiotic } \\
\hline & & OCT-4 & GFR- $\alpha-1$ & C-Kit & CD9 & $\alpha-6$-integrin & Crem-1 & LDH & Protamine & Acrosin & SP-10 \\
\hline 7 days & AVG & $8.04 \pm 0.16$ & $4.94 \pm 0.53$ & $12.59 \pm 1.00$ & $4.74 \pm 1.00$ & $127.77 \pm 21.00$ & 0 & 0 & 0 & 0 & 0 \\
\hline 14 days & $P$ & $* * *$ & $* * *$ & n.s. & $* * *$ & $* * *$ & n.d. & n.d. & n.d. & n.d. & n.d. \\
\hline \multirow[t]{2}{*}{28 days } & AVG & $1.60 \pm 0.46$ & $1.50 \pm 0.62$ & $6.23 \pm 0.20$ & $0.95 \pm 0.50$ & $4.90 \pm 0.18$ & $35.83 \pm 5.00$ & $181.66 \pm 7.00$ & $114.43 \pm 5.00$ & $35.83 \pm 5.00$ & $51.10 \pm 15.00$ \\
\hline & $P$ & $* * *$ & $* * *$ & n.s. & $* *$ & $* * *$ & $* * *$ & $* * *$ & $* * *$ & $*$ & $* *$ \\
\hline
\end{tabular}

Abbreviations: n.d., not determined; n.s., not significant.

Isolated tubular cells from 7-, 14-, 28- and 40-day-old mice were examined by real-time PCR analysis using specific markers for pre-meiotic, meiotic and post-meiotic stages as described in Table 2

The values in the table represent the ratio of expression levels of the related marker to $\beta$-actin of the same sample (as an internal housekeeping control).

Averages (AVG) of RNA levels from three different experiments using the same age cells are presented. Comparisons between RNA levels from tubular cells from 14-, 28-, 40-day-old mice and 7-day-old mice were performed.

$* P<0.05, * * P<0.01, * * * P<0.001$, compared with 7-day-old age.

and b). Lectin-staining revealed that the spermatozoa had normal acrosomes (Figure 5c).

Spermatozoa were present in SACS after 30 days of culture. We were able to detect spermatozoa in 11 out of 16 independent experiments. When analysing microscopic smears from 16 wells after 30 days of SACS, we detected normal-looking spermatozoa in 11 wells. We counted the number of spermatozoa whenever they were present and determined an average count of $15.9 \pm 5.7$ sperm per well.

\section{DISCUSSION}

This study is the first original report revealing the generation of morphologically normal spermatozoa from mouse testicular germ cells in SACS and confirms our recent studies describing a continuous maturation of pre-meiotic germ cells in such a culture system. ${ }^{11,17}$ In our recent study, we have shown that the addition of testicular somatic cells to the lower phase of the agar system resulted in more extensive colony formation and improved spermatogenic differentiation of MACS-enriched GFR- $\alpha$-1-positive cells in the upper phase. ${ }^{11}$ This result was consistent with other studies using conventional culture systems. ${ }^{5,21}$ In the present study, we cultivated a crude single cell suspension of day 7 seminiferous tubules containing all tubular somatic cells and pre-meiotic germ cells. These cells reconstituted into distinct colonies, which expanded during the culture period. Our results indicate that factors present in FCS affect the growth and proliferation of pre-meiotic germ cells. Indeed, FCS stimulates proliferation of mouse gonocytes and bovine type A spermatogonia in vitro. ${ }^{4,5}$

The variability in the detection of markers for pre-meiotic, meiotic and post-meiotic germ cells reveals that the reconstituted and expanding colonies are heterogeneous and that individual colonies may consist of expanding clones of distinct developmental stages of germ cells. However, the detection of markers using RT-PCR and immunohistochemistry revealed the continuous maturation of germ cells into postmeiotic stages. Many colonies contained cells that expressed and stained for meiosis markers such as Crem-1/Crem-1 and Boule. We therefore assume that SACS supports the development of differentiating germ cells from pre-meiotic stages into meiosis, a critical step which is usually blocked under in vitro conditions. Transition into post-meiotic stages was detected again with high variability after longer culture periods. In some experiments, the meiotic and post-meiotic markers were expressed irrespective of the absence or presence of pre-meiotic markers. In our previous studies, we observed that the expansion of diploid germ cells is hormone-dependent, while the meiotic and post-meiotic development appeared to occur independently of hormones. ${ }^{11}$ This observation indicates that expansion of germ cell colonies occurs without the synchronized development of less mature germ cells as would usually occur in the seminiferous epithelium. We assume that the handpicked meiotic and post-meiotic germ cell colonies represent an expansion of pre-meiotic germ cells that were present either in small isolated fragments after enzymatic digestion or re-aggregated when the single-cell suspension was embedded into the agar.

Interestingly, $C D 9$ showed a different expression pattern compared to other markers. Recently, it was reported that CD9 is present in spermatids. ${ }^{22}$ Therefore, it may not be surprising that CD9 expression increases in SACS with time and supports our finding that spermatids and mature sperm are generated in vitro. We could not detect CD9 at the protein level in our system using a polyclonal rabbit anti-mouse antibody (Santa Cruz Biotechnology). We did also not detect CD9 protein in spermatozoa from mature mice.

Our results revealed that prior to culturing (Figure 3e; BC), the cell preparation consisted of germ cells and Sertoli cells, peritubular cells, macrophages and Leydig cells as somatic components. However, the differentiating colonies in SACS (Figure 3e; AC) appeared to be free of somatic cells. However, we observed adherent cells in the bottoms of the culture wells. Thus, FCS components may affect germ cells in SACS directly or may be acting indirectly by causing adherent cells to produce factors that affect the germ cells. In our recent study, we previously showed that the addition of testicular somatic cells to the lower phase of the agar system resulted in more extensive colony formation and improved spermatogenic differentiation of MACS-enriched GFR$\alpha$-1-positive cells in the upper phase, ${ }^{11}$ which was consistent with other studies using conventional culture systems. ${ }^{5,21}$

While the post-meiotic progression was already shown in our previous study using SACS, ${ }^{11}$ here, we present the first original study on the detection of spermatozoa using SACS, which confirms a preliminary analysis that was published in a recent review. ${ }^{17}$ Possible reasons that we failed to detect sperm in our previous manuscript may include difficulty in microscopically detecting sperm in the thick agar layer or the limited number of sperm in the wells. Here, we attempted to quantify the sperm created in the SACS by analysing smears prepared 
Table 4 Expression of spermatogenesis genes in cells from colonies developed in the SACS

\begin{tabular}{|c|c|c|c|c|c|c|c|c|c|c|c|}
\hline & \multicolumn{6}{|c|}{ Pre-meiotic } & \multicolumn{2}{|c|}{ Meiotic } & \multicolumn{3}{|c|}{ Post-meiotic } \\
\hline & Exp & OCT-4 & GFR- $\alpha-1$ & C-Kit & CD9 & $\alpha$-6-integrin & Crem-1 & LDH & Protamine & Acrosin & SP-10 \\
\hline \multirow[t]{7}{*}{ Before culture } & 1 & 5.38 & 2.00 & 12.00 & 6.04 & 132.18 & 0.00 & 0.00 & 0.00 & 0.00 & 0.00 \\
\hline & 2 & 9.77 & 1.60 & 10.85 & 5.47 & 110.09 & 0.00 & 0.00 & 0.00 & 0.00 & 0.00 \\
\hline & 3 & 10.19 & 2.02 & 12.59 & 7.15 & 120.22 & 0.00 & 0.00 & 0.00 & 0.00 & 0.00 \\
\hline & 4 & 0.07 & 6.94 & 3.62 & 10.45 & 21.49 & 0.00 & 0.00 & 0.00 & 0.00 & 0.00 \\
\hline & 5 & 0.00 & 6.48 & 27.02 & 19.24 & 34.43 & 0.00 & 0.00 & 0.00 & 0.00 & 0.00 \\
\hline & 6 & 3.75 & 7.87 & 29.16 & 13.60 & 103.66 & 0.00 & 0.00 & 0.00 & 0.00 & 0.00 \\
\hline & Avg & $4.90 \pm 4.00$ & $4.90 \pm 3.00$ & $15.90 \pm 10.00$ & $10.30 \pm 5.00$ & $87.01 \pm 47.00$ & 0.00 & 0.00 & 0.00 & 0.00 & 0.00 \\
\hline \multirow[t]{17}{*}{ After 14 days } & 1 & 0.01 & 0.25 & 0.00 & 79.66 & 12.01 & 0.00 & 0.00 & 0.00 & 0.00 & 0.00 \\
\hline & 1 & 0.00 & 0.14 & 0.00 & 12.69 & 4.27 & 0.00 & 0.00 & 0.00 & 0.00 & 0.00 \\
\hline & 2 & 0.14 & 0.00 & 0.24 & 22.88 & 4.49 & 0.00 & 0.00 & 0.00 & 0.00 & 0.00 \\
\hline & 2 & 0.00 & 0.07 & 0.00 & 12.26 & 2.27 & 0.00 & 0.00 & 0.00 & 0.00 & 0.00 \\
\hline & 3 & 0.00 & 0.07 & 1.74 & 24.69 & 7.60 & 1.63 & 4.98 & 21.94 & 0.00 & 0.00 \\
\hline & 3 & 0.61 & 0.42 & 3.59 & 15.41 & 0.90 & 0.03 & 0.36 & 21.20 & 0.00 & 0.00 \\
\hline & 4 & 0.00 & 0.00 & 0.11 & 18.07 & 5.80 & 0.00 & 0.00 & 0.00 & 0.00 & 0.00 \\
\hline & 5 & 0.01 & 0.00 & 0.52 & 7.87 & 2.69 & 0.31 & 0.08 & 14.99 & 0.00 & 0.00 \\
\hline & 5 & 0.00 & 0.00 & 0.76 & 6.05 & 14.28 & 1.06 & 0.57 & 5.01 & 0.00 & 0.00 \\
\hline & 5 & 0.09 & 0.01 & 1.58 & 20.33 & 14.78 & 1.01 & 0.66 & 5.34 & 0.00 & 0.00 \\
\hline & 6 & 0.00 & 0.25 & 0.00 & 0.65 & 0.17 & ND & 0.00 & 0.00 & 0.00 & 0.00 \\
\hline & 6 & 0.00 & 0.15 & 0.00 & 0.65 & 0.19 & ND & 0.00 & 0.00 & 0.00 & 0.00 \\
\hline & 6 & 0.00 & 0.15 & 0.00 & 0.54 & 0.11 & ND & 0.00 & 0.00 & 0.00 & 0.00 \\
\hline & 6 & 0.00 & 0.08 & 0.00 & 0.35 & 0.16 & ND & 0.00 & 0.00 & 0.00 & 0.00 \\
\hline & 6 & 0.00 & 0.05 & 0.00 & 0.60 & 0.19 & ND & 0.00 & 0.00 & 0.00 & 0.00 \\
\hline & Avg & $0.06 \pm 0.20$ & $0.11 \pm 0.10$ & $0.57 \pm 1.00$ & $14.90 \pm 19.00$ & $4.70 \pm 5.00$ & $0.40 \pm 0.60$ & $0.40 \pm 1.30$ & $4.60 \pm 8.00$ & 0.00 & 0.00 \\
\hline & $P$ & $* *$ & $* * *$ & $* * *$ & ns & $* * *$ & ns & ns & $\mathrm{ns}$ & ns & $\mathrm{ns}$ \\
\hline \multirow[t]{17}{*}{ After 30 days } & 1 & 5.72 & 0.13 & 0.10 & 243.28 & 61.21 & 12.19 & 0.42 & 55.92 & 264.25 & 242.29 \\
\hline & 1 & 8.43 & 1.48 & 6.83 & 397.77 & 45.75 & 15.73 & 0.76 & 55.55 & 248.70 & 250.29 \\
\hline & 2 & 8.43 & 0.47 & 5.30 & 234.67 & 40.95 & 16.91 & 0.41 & 59.54 & 334.48 & 0.00 \\
\hline & 2 & 0.00 & 1.48 & 0.00 & 136.79 & 40.95 & 0.00 & 0.00 & 0.00 & 0.00 & 0.00 \\
\hline & 3 & 0.45 & 0.00 & 1.32 & 21.64 & 9.49 & 2.39 & 6.43 & 47.37 & 0.00 & 0.00 \\
\hline & 3 & 0.00 & 0.00 & 1.27 & 14.78 & 54.79 & 2.29 & 2.40 & 24.69 & 0.00 & 0.00 \\
\hline & 3 & 0.00 & 0.00 & 1.46 & 34.20 & 51.12 & 6.85 & 7.98 & 47.37 & 0.00 & 0.00 \\
\hline & 4 & 0.00 & 0.47 & 0.00 & 136.79 & 21.58 & 0.00 & 0.00 & 0.00 & 0.00 & 0.00 \\
\hline & 4 & 0.00 & 0.11 & 0.00 & 106.98 & 23.85 & 0.00 & 0.00 & 0.00 & 0.00 & 0.00 \\
\hline & 5 & 0.00 & 0.00 & 2.56 & 37.68 & 145.59 & 19.10 & 5.76 & 138.70 & 0.00 & 0.00 \\
\hline & 5 & 0.00 & 0.15 & 1.75 & 55.94 & 18.58 & 2.72 & 0.00 & 0.00 & 0.00 & 0.00 \\
\hline & 5 & 0.00 & 0.94 & 1.00 & 69.83 & 30.19 & 9.69 & 1.46 & 0.00 & 0.00 & 0.00 \\
\hline & 6 & 0.00 & 0.00 & 0.00 & 157.11 & 60.87 & 0.00 & 0.00 & 0.00 & 0.00 & 0.00 \\
\hline & 6 & 0.00 & 0.00 & 0.00 & 212.97 & 0.00 & 0.00 & 0.00 & 0.00 & 0.00 & 0.00 \\
\hline & Avg & $1.70 \pm 3.20$ & $0.37 \pm 0.50$ & $1.50 \pm 2.10$ & $132.00 \pm 109.00$ & $43.20 \pm 35.00$ & $6.28 \pm 7.00$ & $1.83 \pm 2.80$ & $30.70 \pm 40.00$ & $60.60 \pm 121.00$ & $35.10 \pm 89.00$ \\
\hline & $P$ & ns & \# \# \# & \# \# \# & \# \# & \# & \# & ns & ns & ns & ns \\
\hline & $P$ & ns & ns & ns & $\$ \$ \$$ & $\$ \$$ & $\$$ & ns & $\$$ & ns & ns \\
\hline
\end{tabular}

Abbreviations: ns, not significant.

Colonies that had developed after 14 or 30 days of culture, as described in Figure 3, were examined for expression of genes related to spermatogonial cells (Oct-4, GFR- $\alpha-1$, CKit, CD9 and $\alpha$-6-integrin) and meiotic ( $L D H$ and Crem-1) or post-meiotic markers (Protamine, Acrosin and SP-10).

Gene expression was evaluated by real-time PCR analysis using specific primers for each gene (Table 2 ). The values represent the ratio of expression levels of the related marker to $\beta$-actin within the same sample (as an internal housekeeping gene control).

This table presents the results of six different experiments before culture, six experiments after 14 days of culture in SACS and six experiments after 30 days of culture in SACS. One to five wells from each experiment were examined using real-time PCR analysis.

Averages (AVG) of RNA levels of the different experiments for specific markers (pre-meiotic, meiotic and post-meiotic) were compared after 14 and 30 days of culture in SACS with the RNA levels of the examined marker from tubular cells before culture. RNA levels of the different markers were compared between 14 and 30 days of culture in SACS. *Comparison between the 14-day culture in SACS and before culture.

\#Comparison between the 30-day culture in SACS and before culture.

$\$$ Comparison between the 14- and 30-day cultures in SACS.

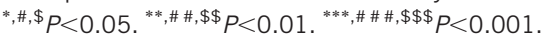

from individual wells. We found that the number of normal-looking sperm was low (about 16 per well per $10^{6}$ cells seeded), although their detection was not a rare event (11 out of 16 experiments). Around 6\% of the cells in the colonies expressed acrosin, as detected by immunofluorescent staining, indicating the presence of spermatids. Because a vast majority of these cells were round, we considered most of these cells to be round spermatids. Although the efficiency of sperm generation appears to be low, the SACS system provides an opportunity to generate a limited number of spermatozoa showing normal sperm morphology and acrosome development under in vitro conditions. We are looking for opportunities to improve the efficiency of the system. In a clinical context, implementing intracytoplasmic sperm 

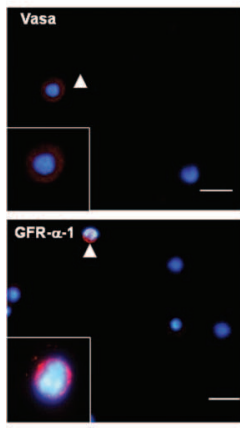

C
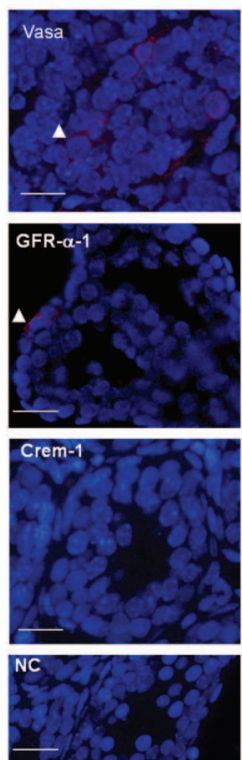
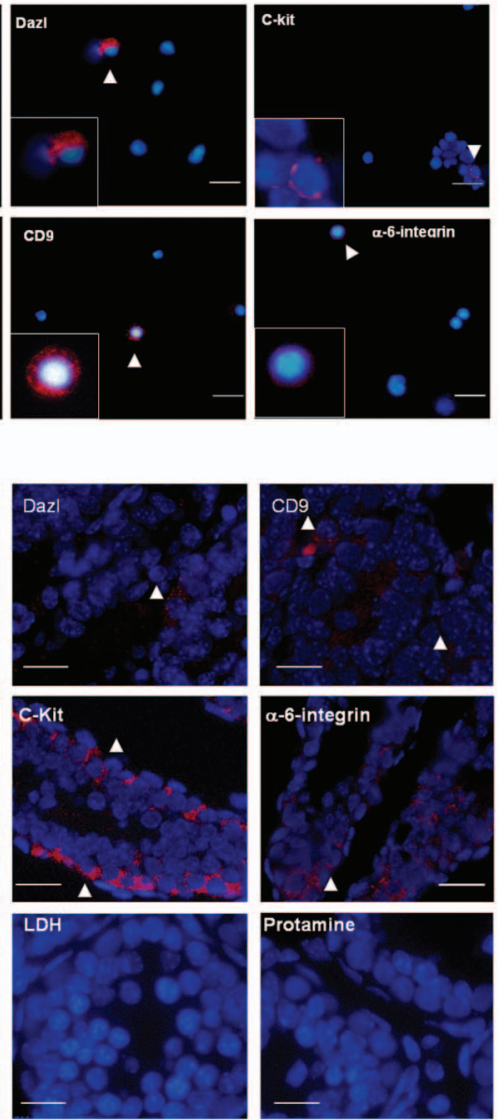

b
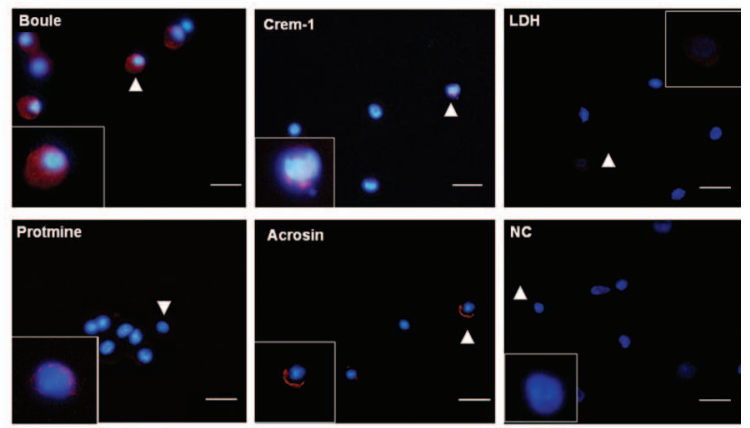

d
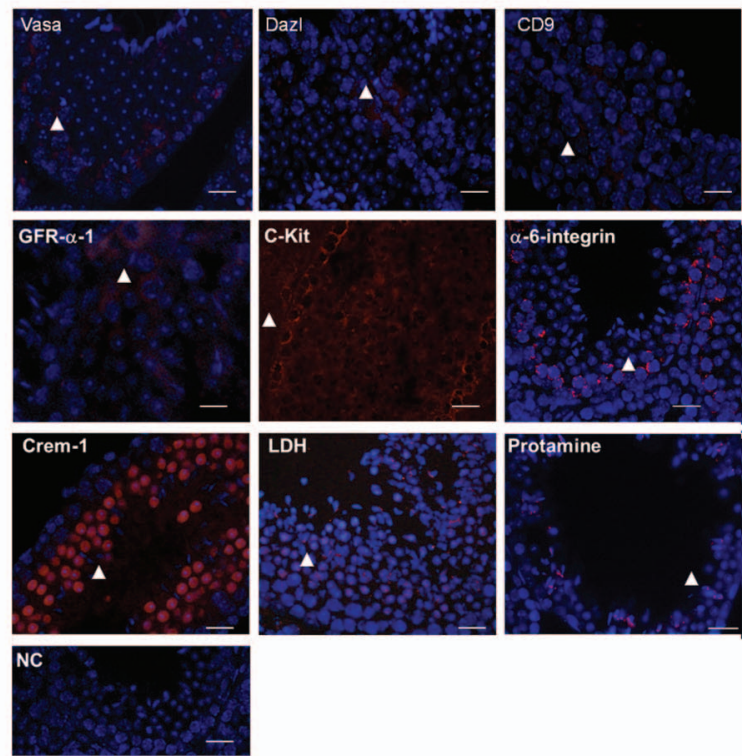

Figure 4 Immunofluorescence staining of cells from colonies developed in the SACS and testicular tissue from immature and mature mice. Colonies that developed within 28 days in culture in SACS were isolated and stained by specific antibodies for different markers of germ cell development by immunofluorescence, including Vasa, Dazl, C-Kit, GFR- $\alpha-1$, CD9, $\alpha$-6-integrin (a), Boule, Crem-1, LDH, Protamine, Acrosin, and the negative control (NC) (b). The presence of Vasa, Dazl, CD9, GFR- $\alpha$-1, C-Kit, $\alpha$-6-integrin, Crem-1, LDH and Protamine, was examined in parallel in testicular tissue from 7-day-old (c) and 8-week-old mice (d). Scale bars $=10 \mu \mathrm{m}$. LDH, lactate dehydrogenase; SACS, Soft Agar Culture System.

injection in assisted reproductive techniques renders even low numbers of sperm sufficient to achieve fertilisation and pregnancy. The low efficiency of the sperm generation of SACS is in agreement with other systems using mouse embryonic stem cells to generate haploid germ cells $(<0.01 \%) .{ }^{23,24}$ However, in contrast to the rather complex strategies used to derive sperm from embryonic stem-like cells, the SACS approach is very simple and none of the ethical concerns that may be associated with the use of embryonic stem cells can be raised.

We only detected sperm after mounting the agar and fixing the cells to slides, which will create a significant problem when these cells are prepared for assisted reproductive technique procedures. A strategy to isolate sperm from the culture system will be an important prerequisite for future development of SACS as a basic research and clinical tool.

Because we have not yet been able to isolate live spermatozoa from SACS, we could not test their fertilisation abilities. In conclusion, our study confirms that SACS can be used as a novel in vitro system for the expansion and maturation of pre-meiotic male germ cells into meiotic and post-meiotic stages. For the first time, we show in vitro generation of morphologically normal spermatozoa with intact acrosomes using
SACS. This unique system could lead to new strategies for the study of spermatogenesis and to new therapies for male infertility.

\section{AUTHOR CONTRIBUTIONS}

MAE designed the experiments; carried out the SACS, qPCR analysis and immunofluorescence staining; performed the statistical analysis; and participated in drafting and revising the paper. EL participated in designing the study, interpreting the data and critically revising the paper for key intellectual content. SS made substantial contributions to the conception and design of the study and interpretation of the data and participated in drafting and critically revising the paper for key intellectual content. MH pioneered the use of SACS for spermatogenesis in vitro, made substantial contributions to the conception and design of the study and the interpretation of the data, and participated in drafting and critically revising the paper for key intellectual content. All authors read and approved the final manuscript.

\section{COMPETING FINANCIAL INTERESTS}

The authors declare that they do not have any competing financial interests. 


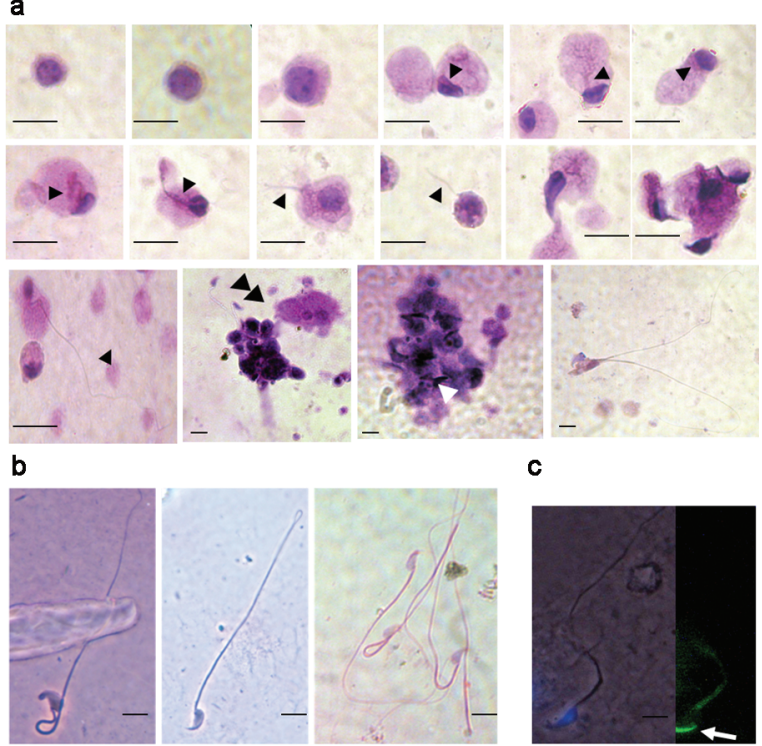

Figure 5 Differentiation of tubular cells to spermatozoa in SACS. Tubular cells were cultured in the SACS as described in Figures $\mathbf{1}$ and $\mathbf{2}$ and evaluated as described in the section on 'Materials and methods'. The presence of differentiated germ cells (a), including spermatozoa (b), in the SACS was examined under the microscope after H\&E staining. More than 10 spermatozoa were determined in each slide (each well). The presence (c) of acrosomes was examined by PNA-FITC staining (greencolour acrosomes). DAPI (blue) staining indicated the heads of the sperm (c). Scale bars $=3-5 \mu \mathrm{m}$. Arrowheads in the upper panel indicate the developing flagellum. H\&E, haematoxylin and eosin; SACS, Soft Agar Culture System.

\section{ACKNOWLEDGMENTS}

This work was partially supported by a grant (No. 1-760-205.2/2002) from the German-Israel Foundation. The authors thank Professor R. Reijo at the University of California, San Francisco, CA, USA, and Professor J. Gromoll at the Institute of Reproductive Medicine, Muenster University, Muenster, Germany, for providing us with Boule antibodies. We also thank Ms Caroline Simon, Faculty of Health Sciences, Ben-Gurion University, for editing the manuscript.

1 Huleihel M, AbuElhija M, Lunenfeld E. In vitro culture of testicular germ cells regulatory factors and limitations. Growth Factors 2007; 25: 236-51.

2 Ehmcke J, Wistuba J, Schlatt S. Spermatogonial stem cells: questions, models and perspectives. Hum Reprod Update 2006; 12: 275-82.
3 Creemers LB, den Ouden K, van Pelt AMM, de Rooij DJ. Maintenance of adult mouse type A spermatogonia in vitro: influence of serum and growth factors and comparison with prepubertal spermatogonial cell culture. Reproduction 2002; 124: 791-9.

4 Hasthorpe S, Barbic S, Farmer PJ, Hutson JM. Neonatal mouse gonocyte proliferation assayed by an in vitro clonogenic method. J Reprod Fertil 1999; 116: 335-44.

5 Izadyar F, den Ouden K, Creemers LB, Posthuma G, Parvinen M et al. Proliferation and differentiation of bovine type A spermatogonia during long-term culture. Biol Reprod 2003; 68: 272-81.

6 Sofikitis N, Pappas E, Kawatani A, Baltogiannis D, Loutradis D et al. Efforts to create an artificial testis: culture systems of male germ cells under biochemical conditions resembling the seminiferous tubular biochemical environment. Hum Reprod Update 2005; 11: 229-59.

7 Tesarik J, Greco E, Mendoza C. Assisted reproduction with in vitro cultured testicular spermatozoa in cases of severe germ cell apoptosis: a pilot study. Hum Reprod 2001; 16: $2640-5$.

8 Sousa M, Cremades N, Alves C, Silva J, Barros A. Developmental potential of human spermatogenic cells co-cultured with Sertoli cells. Hum Reprod 2002; 17: 161-72.

9 Nagano M, Ryu BY, Brinster CJ, Avarbock MR, Brinster R. Maintenance of mouse male germ line stem cells in vitro. Biol Reprod 2003; 68: 2207-14.

10 Kanatsu-Shinohara M, Ogonuki N, Inoue K, Miki H, Ogura A et al. Long-term proliferation in culture and germline transmission of mouse male germline stem cells. Biol Reprod 2003; 69: 612-6.

11 Stukenborg JB, Wistuba J, Luetjens CM, AbuEIhija M, Huleihel M et al. Co-culture of spermatogonia with somatic cells in a novel three-dimensional Soft-Agar-CultureSystem. J Androl 2008; 29: 312-29.

12 Feng LX, Chen Y, Dettin L, Pera RA, Herr JC et al. Generation and in vitro differentiation of a spermatogonial cell line. Science 2002; 297: 392-5.

13 Weaver VM, Peterson OW, Wang F, Larabell CA, Briand P et al. Revision of the malignant phenotype of human breast cells in three-dimensional culture and in vivo by integrin blocking antibodies. J Cell Biol 1997; 137: 231-45.

14 Zhang S. Beyond the Petri dish. Nat Biotechnol 2004; 22: 151-2.

15 Horowitz D, King AG. Colorimetric determination of inhibition of hematopoietic progenitor cells in soft agar. J Immunol Meth 2000; 244: 49-58.

16 Huleihel M, Douvdevani A, Segal S, Apte RN. Different regulatory levels involved in the generation of hemopoietic cytokines (CSFs and IL-6) in fibroblasts by inflammatory products. Cytokine 1993; 5: 47-56.

17 Stukenborg JB, Schlatt S, Simoni M, Yeung CH, Elhija MA et al. New horizons for in vitro spermatogenesis? An update on novel three-dimensional culture systems as tools for meiotic and post-meiotic differentiation of testicular germ cells. Mol Hum Reprod 2009; 15: 521-9.

18 Zeyse D, Lunenfeld E, Beck M, Prinsloo I, Huleihel M. Interleukin-1 receptor antagonist is produced by Sertoli cells in vitro. Endocrinology 2000; 141 1521-7.

19 Huleihel M. Detection of cytokines by immunohistochemistry. In: O'Neill LAJ, Bowie A. Interleukin Protocols (Methods in Molecular Medicine) Totowa, 2001. P157-62.

20 Ganaiem M, AbuElhija M, Lunenfeld E, Cherniy N, Weisze N et al. Effect of interleukin-1 receptor antagonist gene deletion on male mouse fertility. Endocrinology 2009; 150: 295-303.

21 Dirami G, Ravindranath N, Pursel V, Dym M. Effects of stem cell factor and granulocyte macrophage-colony stimulating factor on survival of porcine type $A$ spermatogonia cultured in KSOM. Biol Reprod 1999; 61: 225-30.

22 Ito C, Yamatoya K, Yoshida K, Maekawa M, Miyado K et al. Tetraspanin family protein CD9 in the mouse sperm: unique localization, appearance, behavior and fate during fertilization. Cell Tissue Res 2010; 340: 583-94.

23 Geijsen N, Horoschak M, Kim K, Gribnau J, Eggan K et al. Derivation of embryonic stem cells and male gametes from embryonic stem cells. Nature 2004; 427: 148-54.

24 West JA, Park IH, Daley GQ, Geijsen N. In vitro generation of germ cells from murine embryonic stem cells. Nat Protoc 2006; 1: 2026-36. 